\title{
FLUIDIC CONTROL OF NOZZLE FLOW - SOME PERFORMANCE MEASUREMENTS
}

\author{
John Federspiel, G.E. Aircraft Engines, Cincinnati, Ohio, Linda Bangert and David \\ Wing, NASA Langley Research Center, Hampton, Virginia, and Tim Hawkes, Wright \\ Laboratories, Wright Patterson Air Force Base, Dayton, Ohio
}

\begin{abstract}
Results are presented of an experimental program that investigated the use of a secondary air stream to control the amount of flow through a convergentdivergent nozzle. These static tests utilized high pressure, ambient temperature air that was injected at the throat of the nozzle through an annular slot. Multiple injection slot sizes and injection angles were tested. The introduction of secondary flow was made in an opposing direction to the primary flow and the resulting flow field caused the primary stream to react as though the physical throat size had been reduced. The percentage reduction in primary flow rate was generally about twice the injected flow rate. The most effective throttling was achieved by injecting through the smallest slot in an orientation most nearly opposed to the approaching primary flow. Thrust efficiency, as measured by changes in nozzle thrust coefficient, was highest at high nozzle pressure ratios,NPR. The static test results agreed with predictions obtained prior from PAB3D, a fully viscous computational fluid dynamics program. Since use of such an injection system on gas turbine engine exhaust nozzles would be primarily at high NPRs, it was concluded that fluidic control holds promise for reducing nozzle weight and complexity on future systems.
\end{abstract}

\section{Symbols}

As Injection Slot Area, sq.in.

A8 Primary Nozzle Throat Area, sq.in.

A9 Primary Nozzle Exit Area, sq.in.

Cfg Thrust Coefficient, Ratio of Measured Thrust to the Sum of the Ideal Thrusts of the Primary and Secondary Streams, F / (Fip + Fis)

F Measured Thrust, lbf

Fip Ideal Isentropic Thrust of the Primary Flow Corrected for Real Gas Effects, lbf

Fis Ideal Isentropic Thrust of the Secondary Flow Corrected for Real Gas Effects, lbf
Lf/D8 Length of Divergent Flap From Nozzle Throat to Exit Ratioed to Throat Diameter.

M.S. Model Station, in.

NPR Nozzle Pressure Ratio, Ratio of Primary Nozzle Stagnation Pressure to Atmospheric Pressure

SPR Secondary Pressure Ratio, Ratio of Secondary Stagnation Pressue to Atmospheric Pressure

Injection Slot Exit Width, in.

Wp Primary Nozzle Weight Flow Rate, lbs/sec

Wpo Primary Nozzle Flow Rate with no Secondary Flow, lbs/sec

Ws Secondary Nozzle Weight Flow Rate, $\mathrm{lbs} / \mathrm{sec}$

\section{Introduction}

Recent high performance fighter/attack aircraft have achieved the versatility to operate over a wide range of flight conditions through the use of variable geometry nozzles. These nozzles use mechanical actuators to continuously change nozzle throat and exit areas to optimize performance across a range of Mach number and engine power setting (engine pressure ratio). Especially when accompanied by thrust vectoring capabilities, this independent area control has a substantial impact on nozzle weight, cost and complexity. In order to minimize these penalties, innovative approaches to providing multifunctional capabilities are required. One of the approaches that appears to offer significant benefits is the use of fluidic or secondary flow injection techniques. Fluidic injection has shown the potential to provide multifunctional capabilities while minimizing or eliminating the need for moving mechanical parts in the nozzle, thus potentially reducing nozzle weight, cost and complexity. 
The use of fluidics to provide exhaust nozzle area control has been proposed before, primarily for rocket nozzle applications (i.e., large nozzle expansion ratios and high operating pressures). In references 1 through 3 , fluidic injection used to control rocket nozzle throat area was documented, and reference 4 presents the investigation of fluidic control of the nozzle exit area on a J79 turbojet engine. Results from these studies showed that the percentage area reduction in primary flow was about 1.5 to 2.5 times the injected secondary flow (expressed as a percentage of the primary flow). Typical data from Reference 2, which investigated the effect of slot geometry on throttling are shown in Figure 1.

Figure 1 presents primary weight flow rate, $\mathrm{Wp}$, as a function of secondary weight flow rate, Ws. Both flows are normalized by a reference flow, Wpo, which is the flow through the primary nozzle with no secondary injection. By definition then, $\mathrm{Wp} / \mathrm{Wpo}$ is equal to 1.00 when Ws/Wpo is zero. A dotted "No Throttling" line is shown on the chart. This shows the characteristic line that would occur if each unit of secondary flow exactly displaced an equal unit of primary flow. In that case, total flow through the nozzle throat would not change.

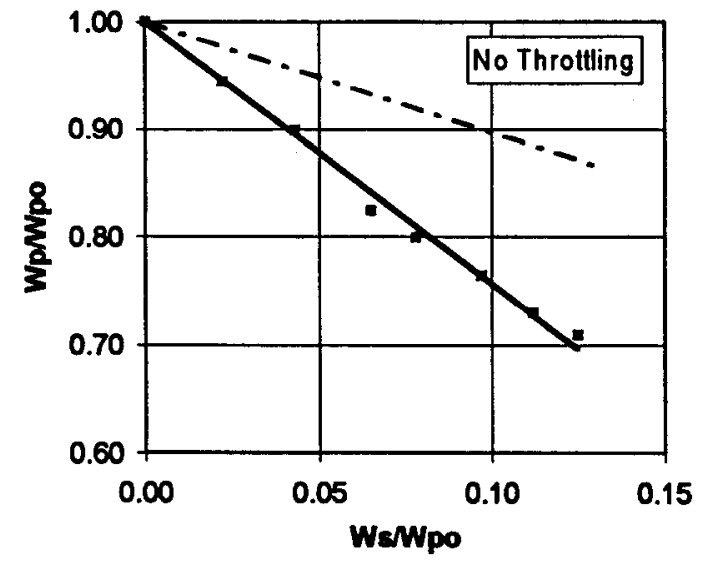

Figure 1. Throttling Performance Data from Reference 2.

Conclusions drawn from the experimental work in Reference 2 and from follow-on work reported in Reference 3 indicated;

a) that the secondary injection needed to take place at the geometric nozzle throat for throttling to occur,

b) that the injection orifice geometry (slots, multiple holes, asymmetric arrangements) had very little effect on the throttling characteristic, and

c) that the angle of injection had a strong influence on the throttling and was most effective as it approached an opposing direction to the primary flow.

Further, it was found that as long as the nozzle was choked, the downstream geometry had little influence on the measured flow characteristics. This was important, since the data were obtained on nozzles with expansion ratios much larger then those of interest for current turbine engines. However, the impact of secondary flow injection on thrust coefficients was largely ignored.

This paper presents the results of both sub-scale experimental and computational fluid dynamics (CFD) investigations that were conducted to determine the effect of fluidic control of nozzle throat area on the thrust coefficient of an axisymmetric convergentdivergent nozzle. The experimental study was conducted in the static-test facility of the NASA Langley 16-Foot Transonic Tunnel. Two independently controlled and metered high pressure, ambient temperature air flows exhausted to atmosphere through a nozzle having an expansion ratio of 1.15. The "fluidic control" (secondary) air was introduced at the throat of the nozzle through an annular slot. The secondary slot size and the injection angle relative to the thrust axis were varied. Measured parameters included resultant thrust, secondary and primary flow rates and internal nozzle wall static pressures. However, the wall static pressures are not presented in this paper.

In the CFD portion of the study, the code PAB3D (reference 5) was applied to this geometry to evaluate the effectiveness of this code in properly modeling the complex flow fields associated with fluidic injection. Since this code was originally developed to model the interactions between airframe and propulsive flow fields, it was thought that PAB3D would also be suited to modeling multiple interacting internal flows. Both pre-test predictive solutions and post-test analysis solutions were obtained.

\section{EXPERIMENTAL APPARATUS AND PROCEDURES}

\section{The Model}

Nozzles for current turbine engines generally have much lower expansion ratios than the rocket nozzles of the studies referenced previously. Additionally, the 


\section{Test Model}

- Axisymmetric, Convergent - Divergent

- $A 9 / A 8=1.15$

- $L f / D 8=0.7$

- Model Throat Size

- Diameter $=3.25$ inches

- Area $=8.296$ sq. in.

- Fluidic (Secondary) Slot Sizes

- Small Slot throat, $t=0.07$ in. As/A8 $=0.087$

- Large Slot throat, $t=0.25$ in. $A s / A 8=0.31$

- Fluidic Injection Angle

- $30^{\circ}$ and $60^{\circ}$ (Relative to Horizontal)

Figure 2. Nozzle Geometry and Dimensions

secondary slot would need to be sized to accommodate pressures and temperatures from a range of available sources (e.g., fan bleed, high pressure compressor stage bleed, nozzle approach flow). As mentioned previously, the reduction in nozzle expansion ratio was not expected to affect the throttling characteristics.
However, the range of slot areas of interest was much broader than those previously reported. An effect on throttling characteristics was anticipated.

The impact of geometry changes on thrust characteristics had not been adequately demonstrated, and in this application, expansion ratio was expected to impact the resuits.

The subscale model used in the experimental investigation is described in figures 2 and 3 . The nozzle was axisymmetric, which afforded economies in fabrication and some simplicity in mathematical modeling for the CFD effort. The expansion ratio was 1.15 and the primary nozzle throat area was 8.296 square inches. Two slot sizes were included. The range of slot sizes is representative of those that could be expected, depending on the source of the fluidic injection air. Two injection angles, which represent the range of interest that can easily be accommodated in a fixed geometry nozzle, were provided so that the effect on thrust could be addressed. The 30-degree and 60-degree injection angles were defined with respect to the primary nozzle flow axis. Both angles represent upstream injection with the 30-degree configuration injecting in a more upstream direction.
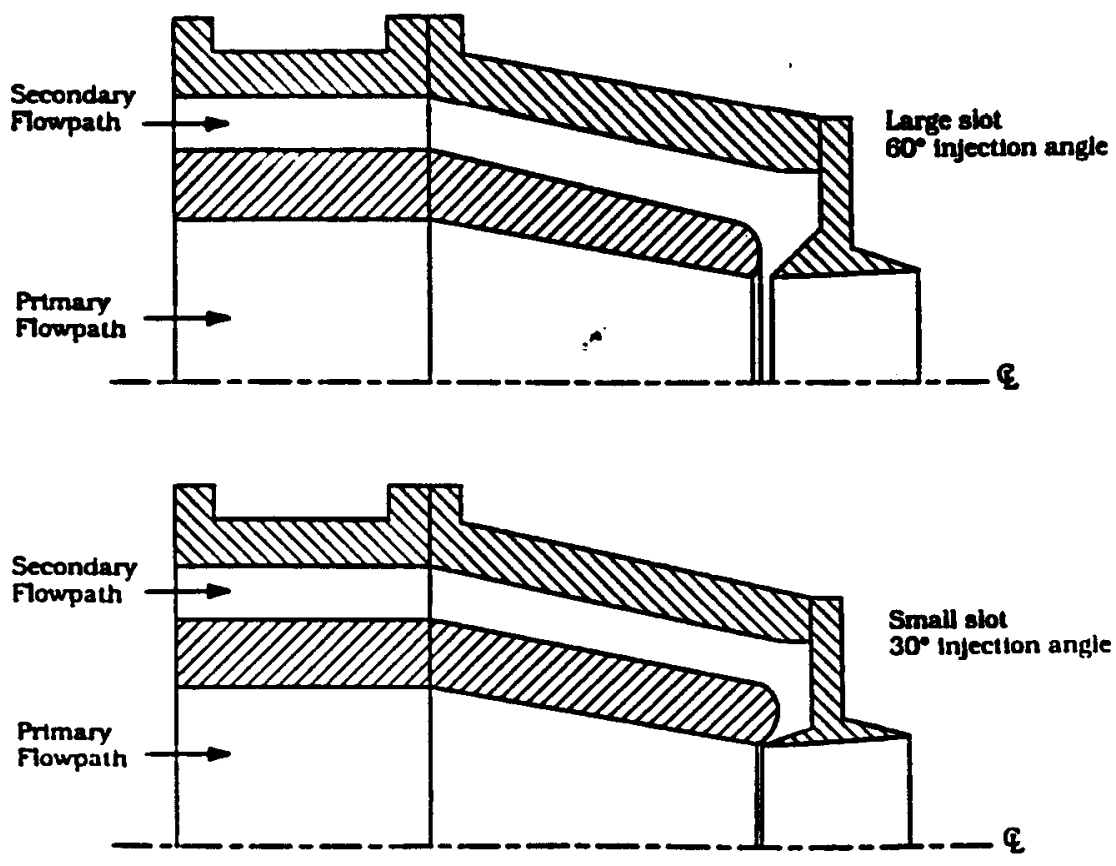

Figure 3. Section View of the Model Hardware 


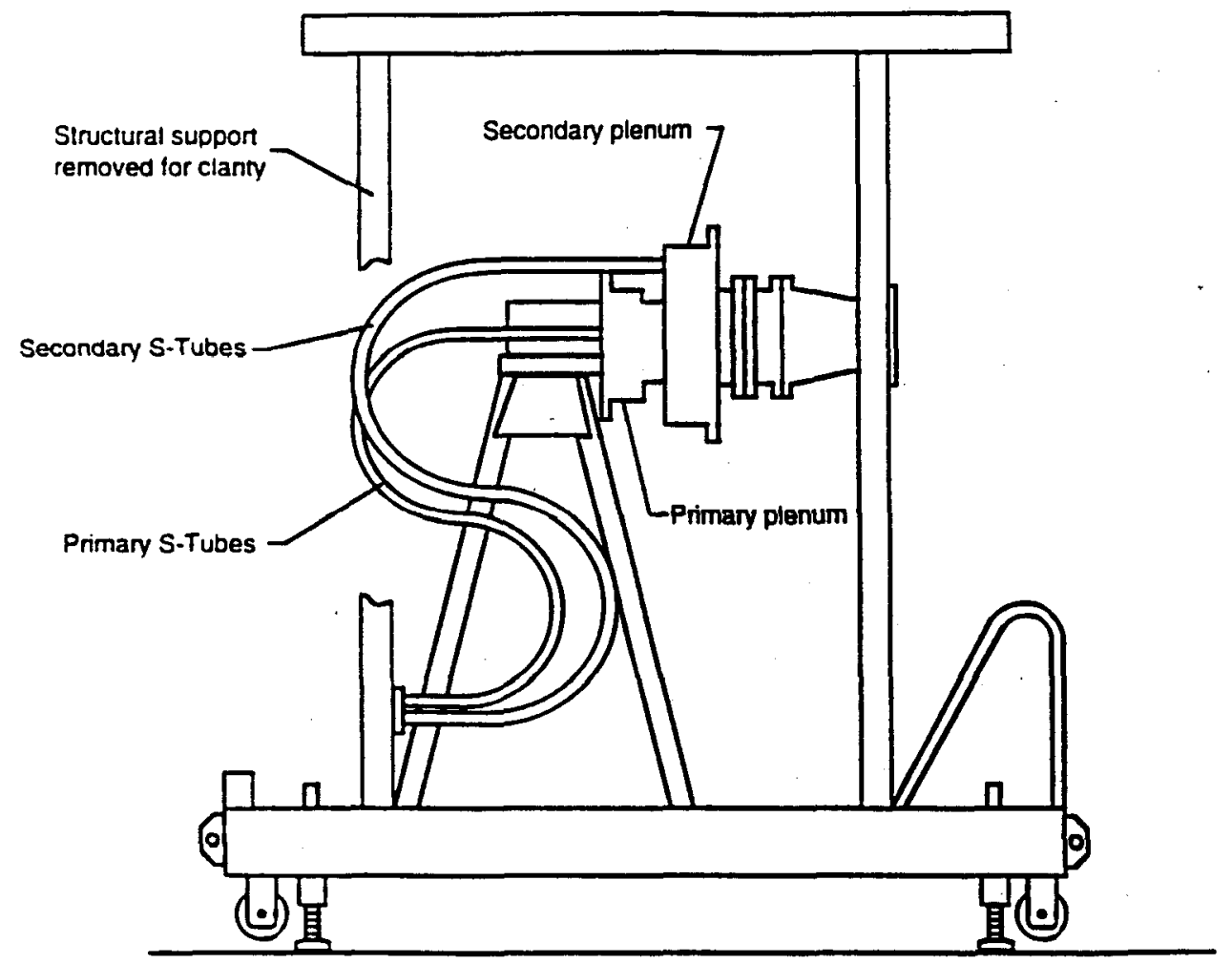

Figure 4a. Static Test Stand with Dual-Flow Propulsion Simulation System

\section{Test Apparatus}

The fluidic area control nozzle was tested in the static test stand of the NASA Langley 16-Foot Transonic Tunnel. Testing is conducted in a large room with the jet exhausting to the atmosphere. The test stand, shown in Figure 4(a), is an axisymmetric single-engine propulsion simulation system with dual co-annular ducts mounted on a six-component strain-gage force balance. Two independently controlled high-pressure air supplies cross from the non-metric to the metric portion of the dual-flow propulsion simulation system through two pairs of S-shaped stainless steel tubes (Stubes). Each of the two air systems contains a heat exchanger to maintain the flow temperature at approximately $540^{\circ} \mathrm{R}$, and a multiple critical venturi system to measure weight flow rate. The primary air system supplied air at up to $21 \mathrm{lbs} / \mathrm{sec}$, and the secondary air system provided air at up to $15 \mathrm{lbs} / \mathrm{sec}$.

As shown in Figure 4(b) the primary air supply passes from the S-tubes through eight sonic nozzles which exit radially into a cylindrical axial chamber, through a choke plate and into an instrumentation section before entering the nozzle being tested. The secondary air supply passes through twelve sonic nozzles which exit into a toroidal chamber (co-annular to the primary chamber) then through a choke plate and into an instrumentation section before entering the test nozzle.

\section{Instrumentation}

Forces and moments downstream of MS 0.00 were measured with a six-component strain-gage balance located on the centerline of the propulsion simulation system. Primary jet total pressure was measured by a nine-probe rake in the instrumentation section. Secondary total pressure was measured by four pressure probes in the injection slot, and these pressures were used to determine secondary pressure ratios. Total temperatures were measured by thermocouples located in the primary and secondary instrumentation sections. Weight flow rate of the high pressure air supplied to the model was measured by a multiple critical venturi in each of the two air systems.

\section{Data Reduction}

Fifty samples of data were recorded for each data point at a rate of ten samples per second, and the averages were used in the data reduction computations. Balance force measurements were initially corrected for model weight tares and isolated balance interactions. Additional interactions were computed by recalibrating the balance after it was installed in the test stand to 


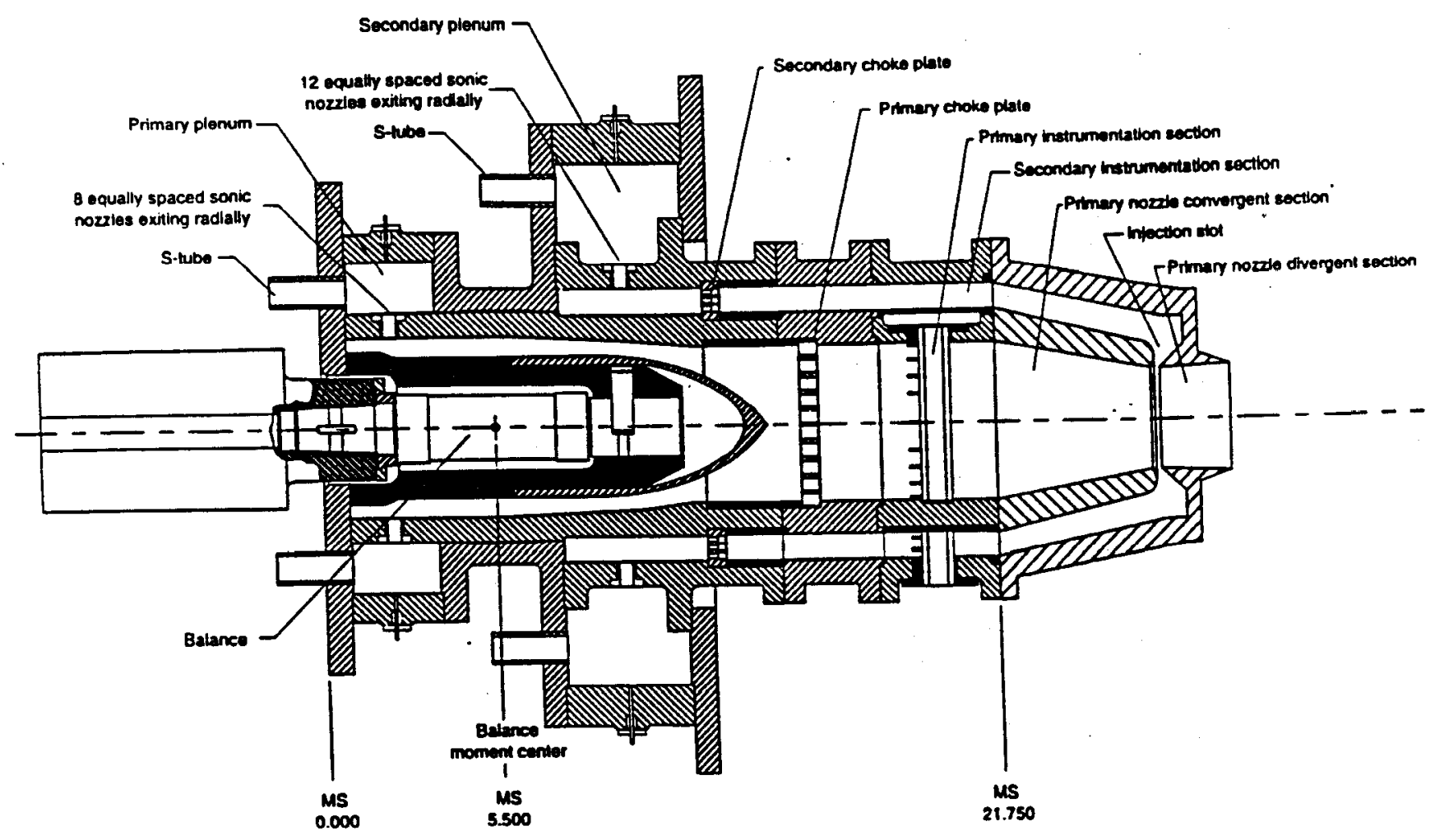

Figure 4b. Dual Flow Propulsion Simulation System with Nozzle Attached

account for the restraint of S-tubes on the balance. In addition to providing a set of "installed" interactions, this calibration accounted for the effects of pressurization (jet operation) and momentum transfer (nozzle throat area). The S-tubes were designed to be flexible enough to minimize the static restraint on the balance, yet retain enough rigidity to withstand the pressurization during jet operation and minimize the effect of pressurization on static restraints. However, residual tares still existed and were a result of the tendency of the S-tubes to deform under pressurization. These residual tares were determined by testing Stratford convergent nozzles with known performance over a range of expected internal pressures and externally applied forces and moments. Prior to accounting for these tares, the force balance accuracy is generally quoted as being no worse than 0.5 percent of the full-scale value of a particular component. For this investigation, the uninstalled balance accuracy for axial force was $6 \mathrm{lbf}$.

\section{Methodology}

The test approach was to establish the primary flow with a discrete primary nozzle pressure ratio, NPR, and then to increase the secondary weight flow rate, taking data at discrete intervals of secondary pressure ratio, SPR. SPR was determined from the total pressure probes in the nozzle slot, and the lowest value of SPR obtainable was dependent on NPR. All data were obtained with NPR and SPR in increasing order.

\section{Computational Results}

Pre-test predictions were obtained for two nozzle configurations; the 60-degree injection angle with both the large and small slot. Numerical solutions were obtained using a three-dimensional (3-D) NavierStokes code, PAB3D, developed by NASA Langley Research Center and Analytical Services and Materials, Inc. The PAB3D code solves the 3-D, Reynolds-averaged, simplified Navier-Stokes equations using either a time marching technique or space marching procedures. The PAB3D code also includes both algebraic and two-equation turbulence models. Time dependent solutions using Roe's flux splitting scheme and a two-equation ( $k-e)$ model were used in this study

Nozzle performance predictions are given in terms of mass flow ratio and thrust ratio. Figure 5 shows nozzle flow ratio performance for a range of operating conditions. Note that the data for each slot size has a unique slope with the smaller slot (operating at higher pressure ratios) having more effective throttling. Also 
note that the throttling for both configurations is completely independent of nozzle pressure ratio, NPR

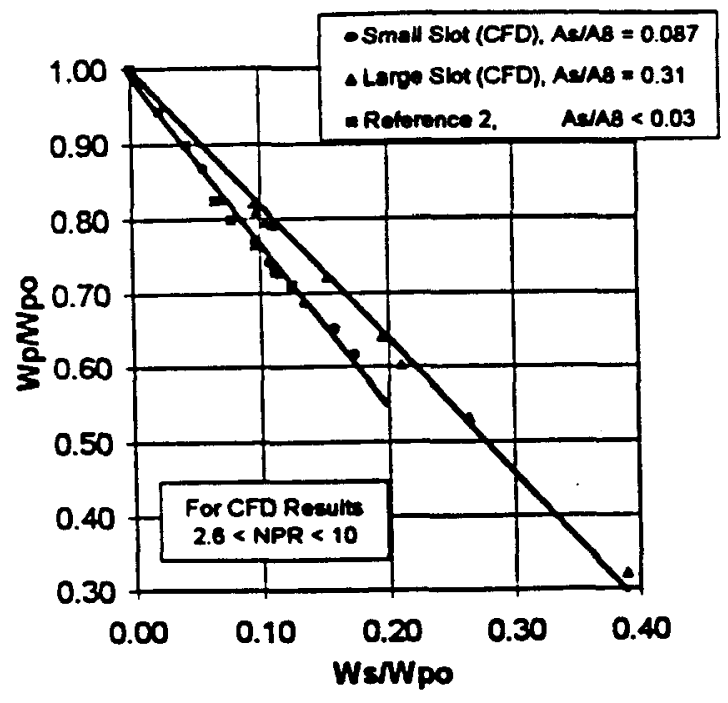

Figure 5. Results of the CFD Investigation Overlaid on the Data from Reference 2

This agrees well with data from Reference 2 which also demonstrated independence from nozzie pressure ratio.
To examine the efficiency of the throttling process, the change in gross thrust coefficient, Delta Cfg, was used. The change caleulated is between $\mathrm{Cfg}$ for no secondary flow and Cfg for a discrete value of secondary flow. A positive value of Delta $\mathrm{Cfg}$ is a decrease in thrust coefficient for the flowing condition.

The results of the computations are shown in Figures $6(a), 6(b)$ and $6(c)$ for nozzle pressure ratios of $2.8,6.0$, and 10.0 respectively. In both the large and small slot configurations, losses were a function of the primary nozzle pressure ratio The highest thrust penalties cocurred at the lowest pressure ratios. At a nozzle pressure ratio of 10.0, where the nozzle is operating less then fully expanded and well above its design pressure ratio of 3.6, the fluidic throttling showed a slight gain in thrust coefficient at the lower slot flow ratios. The smaller slot configuration had generally higher levels of thrust loss, a cost for its higher throttling efficiency.

\section{Test Results}

The throttling characteristics for the 60-degree injection angle configurations are shown in Figure 7
NPR $=28$
Figre6a

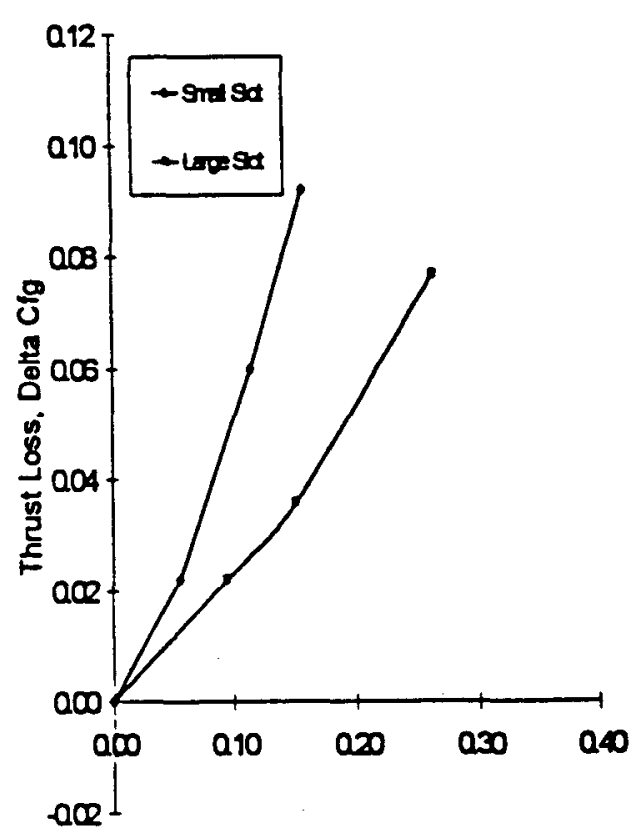

Ws/Wo

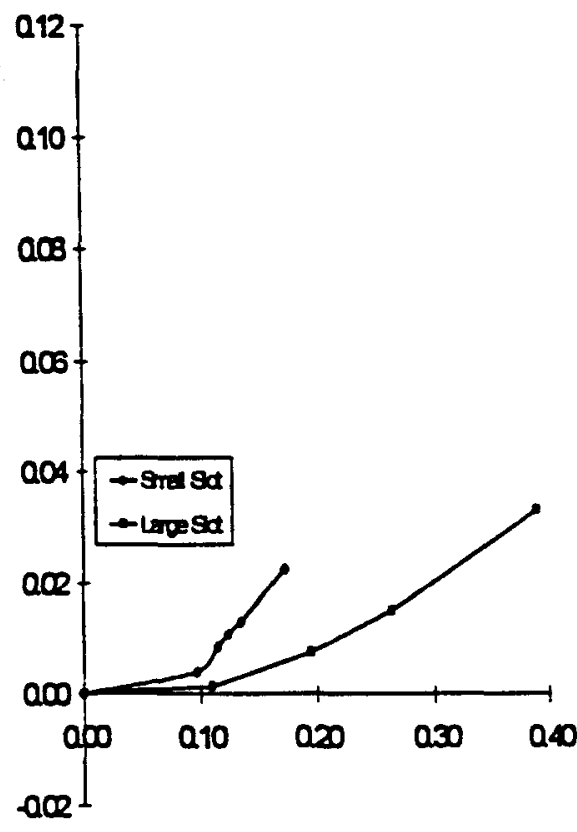

Ws/Wpo
$N P R=10$

Figre6c
NPR=6

Figre6b

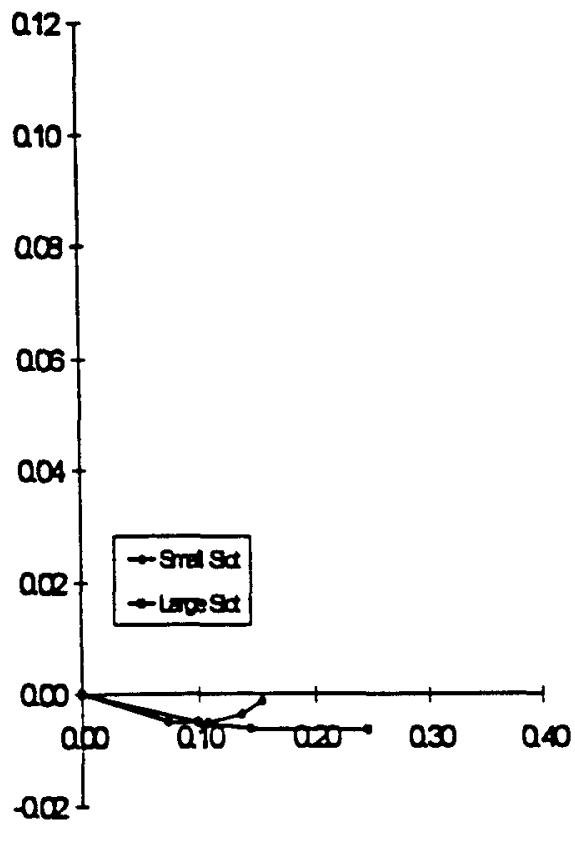

Ws/Wo

Figure 6. Losses in Thrust Coefficient as a Function of Slot Flow as Calculated with the PAB3D computer code. 
with the test data overlaid upon the previously shown CFD results.

Agreement is excellent and confirms the significant effect that slot size has upon throttling. Throttling is independent of NPR for each slot configuration, which agrees with the CFD predictions.

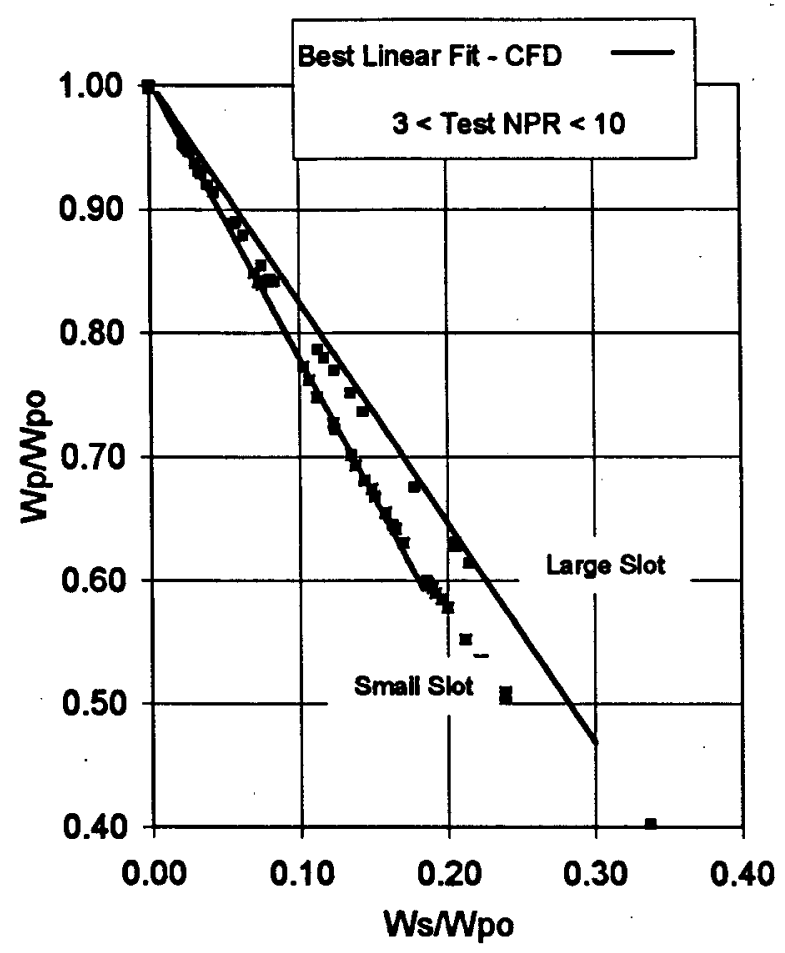

Figure 7. Throttling Test Data Agreed with CFD Results

In Figure 8 data from the large slot configurations for the 30 and 60-degree injection angle configurations are

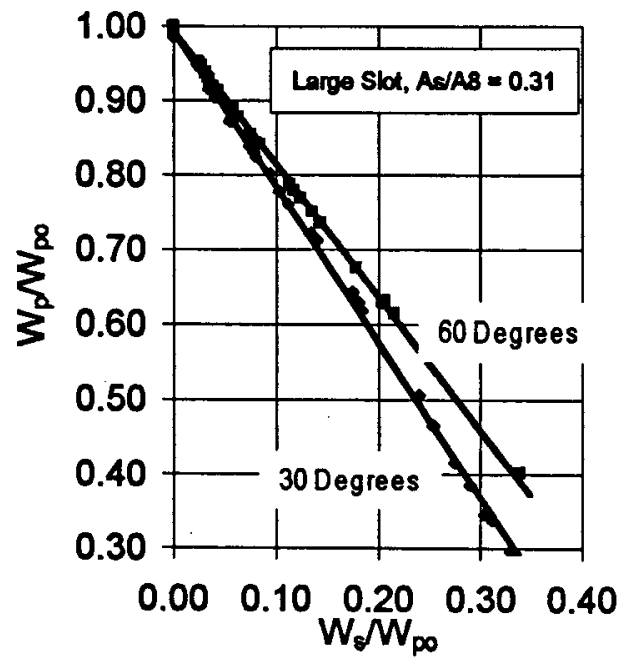

Figure 8. The 30 Degree Slot Showed the Best. Throttling Performance compared. It may be noted that the 30-degree injection angle (oriented more upstream) provides more effective throttling, agreeing with the conclusions reached in Reference 2. Again, the data from all NPRs fall along a single characteristic line. Although the data are not shown, the smaller slot exhibited a similar characteristic, with the 30-degree injection angle again providing more effective throttling. A large range of control was demonstrated with the 30 degree injection angle configuration which reduced the primary flow

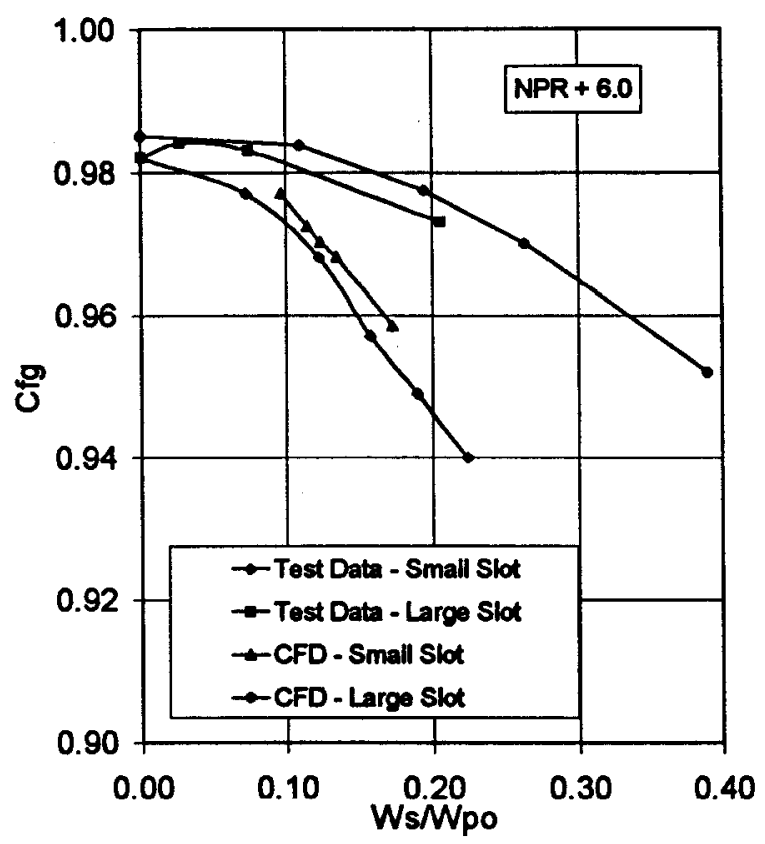

Figure 9. CFD Predictions Agreed Well with the Thrust Coefficient Test Data.

rate as much as $\mathbf{7 0} \%$.

Figure 9 shows thrust coefficient data from the experimental and CFD investigations for the 60 degree configurations at NPR $=6.0$. Again there is excellent agreement in both magnitude and trends with varying secondary flow. The lower thrust losses with the larger slot size were confirmed experimentally for both injection angles.

The larger matrix of test data points is utilized in Figure 10 to give a clearer demonstration of how thrust penalties are minimal at high NPRs. Here data has been cross plotted at constant values of secondary flow ratio for the 60 degree large slot configuration. 
It can be clearly seen that at NPR $>6$, thrust coefficients change little for a wide range of secondary flows. This trend held true for all of the configurations tested.

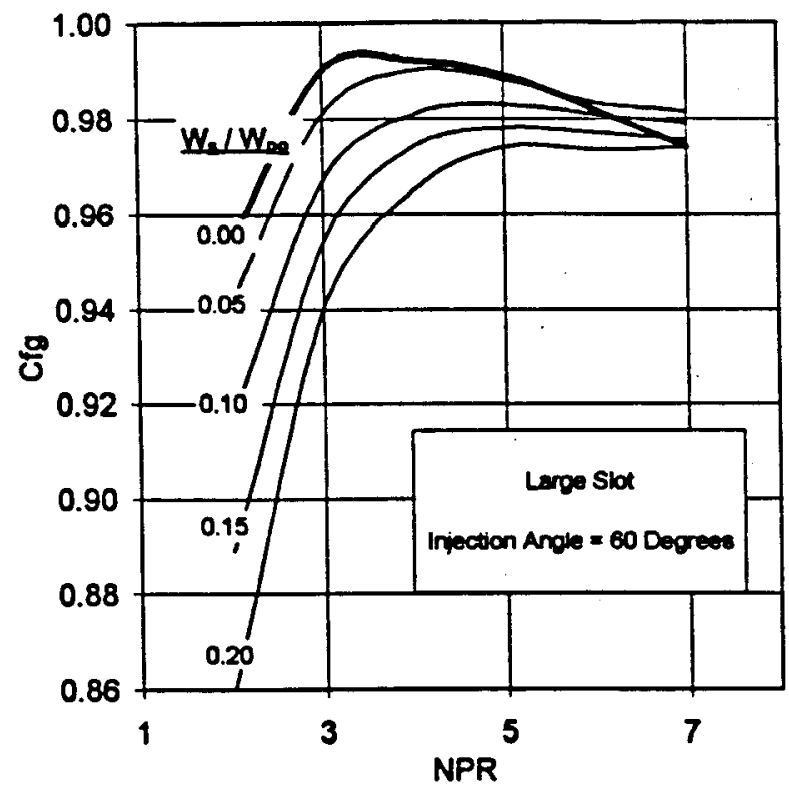

Figure 10. Thrust Characteristics at Constant Values of Injected Flow Rate

\section{Concluding Remarks}

Test results indicated that flow through a choked convergent-divergent nozzle can be controlled over a wide range by injection of a secondary high pressure stream near the throat of the nozzle. A reduction of as much as $70 \%$ of the primary flow rate was demonstrated during testing. With higher slot pressures and flow rates, this value could likely be increased. The effectiveness of the throttling was enhanced as the angle of injection was oriented more upstream toward the approaching primary flow. This is consistent with trends noted in the historical literature.

The test results also demonstrated that flow control is possible with a variety of slot sizes. However, higher pressures which allow smaller slot areas to be used clearly require lower flow rates for a given level of control. The size of the secondary supply would therefore be minimized, leading to a more compact installation.

Thrust losses caused by fluidic area control were shown to be small at the high nozzle pressure ratios where such controls would be used in flight. With the attendant weight savings and part reduction, it is quite possible that a net gain in performance could be realized.

Finally, CFD solutions were shown to accurately predict the measured flow and thrust characteristics observed in the test. Further investigations into improvements in slot arrangement and geometry may be undertaken using these tools, with a high degree of confidence.

\section{References}

1. Zumwalt Glen W. and Jackomis, William N., "Aerodynamic Throat Nozzle for Thrust Magnitude Control of Sloid Fuel Rockets," ARS Journal, pp. 1934 -1936, December, 1962.

2. Blaszak, John J. and Fahrenholz, Fred E., "Rocket Thrust Control by Gas Injection," Massachusetts Institute of Technology Naval Supersonic Laboratory Technical Report 430. November 1960.

3. Gunter, Fred L. and Fahrenholz, Fred E., "Final Report on a Study of Rocket Thrust Control by Gas Injection.," Massachusetts Institute of Technology Naval Supersonic Laboratory Technical Report 448. May 1961.

4. Hawthorne, R, "Jet Exhaust Controlled by 'Striction' Nozzle," Aviation Age, Vol 27, No. 1, Jan 1957, pp. 46-49 1957

5. Abdol-Hamid, K. S., "A Multiblock/Multizone Code (PAB3D-v2) for the Three-Dimensional NavierStokes Equations: Preliminary Applications," NASA CR-182032, 1990 